\title{
A Novel Multicompartment Dissolution Apparatus for Evaluation of Floating Dosage Form Containing Poorly Soluble Weakly Basic Drug
}

\author{
Dr. Rajesh K. Parikh ${ }^{1,2}$, Dhaivat C. Parikh ${ }^{1}$, \\ Renish R. Delvadia ${ }^{1}$, and Sanjay M. Patel ${ }^{1}$
}

\begin{abstract}
Incorporation of a weakly basic drug into a gastro-retentive dosage form yields better biomedical benefits compared to incorporation into a conventional controlled release dosage form. Poorly soluble weakly basic drugs may precipitate upon entry into the small intestine, and this can affect absorption. To study drug release from floating dosage forms and simultaneously examine the effect of $\mathrm{pH}$ change on poorly soluble weakly basic drugs, a novel multicompartment dissolution system was developed by modifying beakers. The system consists of three serially placed compartments providing gastric, intestinal, and absorption compartment to mimic the in vivo dissolution and absorption in the gastrointestinal tract. A dosage form remained buoyant in the gastric compartment, released drug was allowed to transfer to the intestinal compartment, and soluble drug in the intestinal compartment was allowed to transfer to the absorption compartment through a filter. Dissolution profiles of $75 \mathrm{mg}$ cinnarizine in conventional and floating tablets were studied. The results of conventional tablet showed that although cinnarizine was completely dissolved in the gastric compartment, approximately $50 \%$ of cinnarizine was precipitated in the intestinal compartment. A floating cinnarizine tablet showed complete release within 24 hours with nearly zero order release rate, and no precipitation observed in the intestinal compartment, giving $100 \%$ of cinnarizine transferred into the absorption compartment. The floating controlled release of poorly soluble weakly basic drug may give considerable biomedical benefits over conventional tablet formulation, which was demonstrated by the proposed novel multicompartment system. Variability of volume in the gastric and intestinal compartments was studied by making further modification in the apparatus. The proposed system may give good in vivo - in vitro correlation, as attempts can be made to mimic in vivo conditions such as gastric volume, gastric secretion, gastric emptying to the intestine, and intestinal absorption.
\end{abstract}

\section{Introduction}

O ral controlled release $(\mathrm{CR})$ dosage forms generally have a transit time of $1-3$ hours in the stomach, 3-5 hours in the intestine and 4-11 hours in the colon(1). However, some drugs require more retention time in the stomach for better results. Gastro-retentive drug delivery is superior for drugs such as (a) drugs having a narrow absorption window, (b) drugs having their local effect in stomach (for example, antacids and anti helicobacter pylori agents), (c) drugs having $\mathrm{pH}$-dependent stability, (d) drugs having low solubility at intestinal $\mathrm{pH}$, and (e) drugs having colonic degradation $(2,3)$. Approaches to achieve higher gastric residence time include (a) low density systems that float on gastric fluid, (b) bioadhesive systems that adhere to mucosal surface of stomach, (c) expandable systems that increase in size by swelling or unfolding to retard passage through the pylorus, (d) high density systems that sink in the lower curvature of the stomach, (e) magnetically controlled systems that operate by incorporation of magnetite oxide or coated magnets (4-6).

Weakly basic drugs have lower $\mathrm{pK}_{\mathrm{a}}$ values and remain in ionized form at stomach $\mathrm{pH}$ having higher solubility, and in un-ionized form at intestinal pH having lower solubility (7).
According to $\mathrm{pH}$ partition theory (14), drug is absorbed in un-ionized form, thus weakly basic drug absorbs from the intestine. When weakly basic drug is incorporated in a conventional CR dosage form, only a fraction of the drug is dissolved due to lesser solubility at its absorption site, such as the intestine. Incorporation of weakly basic drug into a gastro-retentive dosage form is beneficial over a conventional CR dosage form so that released drug continuously reaches its absorption site such as the intestine (8). Cinnarizine is a weak base $\left(\mathrm{pK}_{\mathrm{a}} 1.95,7.5\right)$ having higher solubility at lower $\mathrm{pH}(0.29 \mathrm{mg} / \mathrm{mL}$ in $0.1 \mathrm{~N} \mathrm{HCl})$ and lower solubility at higher $\mathrm{pH}(0.002 \mathrm{mg} / \mathrm{mL}$ in phosphate buffer $\mathrm{pH} 7.2)$, and thus is selected as the model drug for the floating dosage form $(9,10)$.

In vitro dissolution testing is generally carried out for quality control purposes and to establish an in vivo - in vitro correlation. The currently used in vitro dissolution method for the floating dosage form is conducted at a constant $\mathrm{pH}$ 1.2 to mimic the stomach environment. The general prediction is that when drug is dissolved in vitro, it is considered that the drug is also absorbed in vivo. However, in vivo, the drug is exposed to varying dissolution environments in the gastrointestinal (Gl) tract. Particularly, the $\mathrm{pH}$ in the $\mathrm{Gl}$ tract

${ }^{1}$ Department of Pharmaceutics and Pharmaceutical Technology,

${ }^{2}$ Corresponding author. 


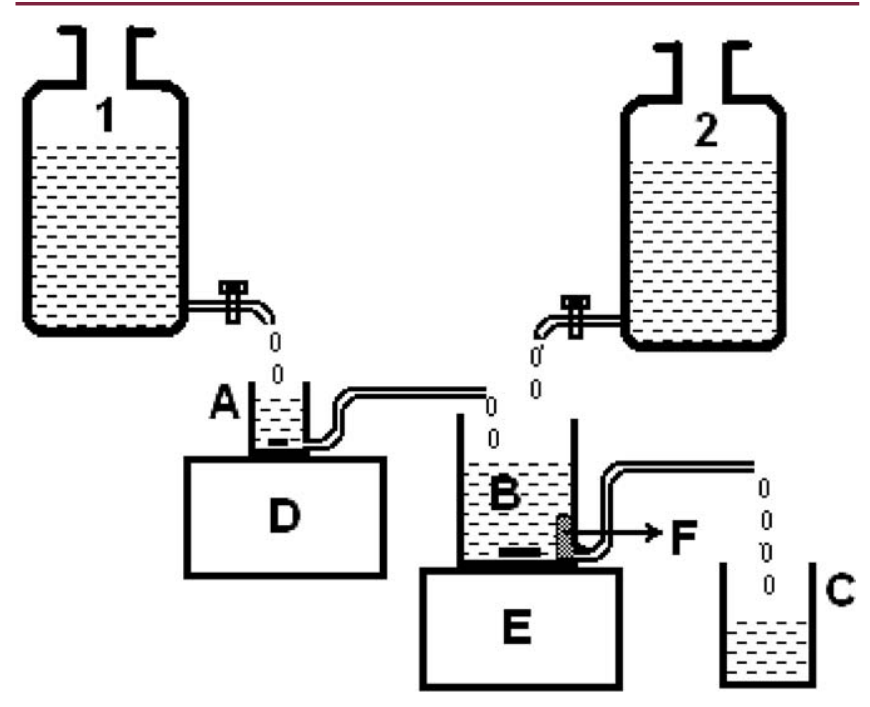

Figure 1. Novel Multicompartment Dissolution Apparatus.

1 - Gastric Reservoir, 2 - Intestinal Reservoir, A - Gastric Compartment,

$B$ - Intestinal Compartment, $C$ - Absorption Compartment,

$D$ and $E$ - Magnetic stirrer with heating facility, $F$ - filter.

changes from acidic in the stomach to neutral in the intestine. Thus, when a weakly basic drug moves from favorable $\mathrm{pH}$ condition (higher solubility) of the stomach to a less favorable $\mathrm{pH}$ condition (lower solubility) of the intestine, precipitation is observed and drug absorption may be hindered.

To avoid problems like floating and/or sticking to paddle or vessel associated with dissolution study of low density dosage forms, various modifications of USP dissolution apparatus have been tried such as (a) paddle at upper surface of dissolution media, (b) sinkers made by attaching a small, loose piece of non-reacting material, such as a few turns of wire helix, around the dosage form, (c) use of one or two meshes over and below the dosage form, (d) keeping mesh on indented vessel $(11,12)$. However, all of these modifications are limited in their ability to mimic in vivo condition. Recently, a novel in vitro dissolution method has been developed by modification of Rossett-Rice apparatus to mimic in vivo conditions (13).

Several dissolution systems have been developed to study dissolution of drugs with $\mathrm{pH}$-dependent solubility. To study dissolution of weakly basic drugs, specific systems have been developed such as the transfer model (7) and multicompartment dissolution apparatus $(9,15,16)$.

More sophisticated devices have also been used such as fiberglass dialysis (17) and Caco-2 cell membrane (16) to simulate in vivo absorption of drug.

However, none of these dissolution systems is suitable to study the floating ability of the controlled release gastroretentive dosage form along with simultaneous study of the effect of $\mathrm{pH}$ change on a weakly basic drug. Hence, a novel multicompartment dissolution apparatus has been developed.

\section{Materials and Methods \\ Materials}

Cinnarizine (Carol Remedies, Ahmedabad, India), HPMC K100 (Zydus Cadilla, Ahmedabad, India), sodium bicarbonate (Samir Tech. Chem. Pvt. Ltd., Ahmedabad, India), boric acid (ASES Chemical works, Jodhpur, India), and potassium chloride (ACS Chemicals, Ahmedabad, India) were used.

\section{Preparation of floating tablets}

Cinnarizine (75 mg), HPMC K100 (100 mg), and sodium bicarbonate $(25 \mathrm{mg}$ ) were mixed thoroughly. The mixture was directly compressed to make a tablet using a singlestroke tablet machine (Cadmach Machinery Ltd., Ahmedabad).

\section{Novel multicompartment dissolution method}

A novel multicompartment dissolution apparatus shown schematically in Figure 1, comprises a series of three compartments: a gastric compartment, an intestinal compartment and an absorption compartment. A gastric compartment was designed by modification of a glass beaker (100-mL capacity) at the base by adding an S-shaped side arm such that the beaker can hold $70 \mathrm{~mL}$ of $0.1 \mathrm{~N} \mathrm{HCl}$. An intestinal compartment was designed by similar modification, from a glass beaker (500-mL capacity) such that it can hold $400 \mathrm{~mL}$ of 'pH adjusted intestinal fluid. A volumetric cylinder was placed as an absorption compartment to collect fluid coming out of the intestinal compartment. A Whatman filter was placed at the bottom output of intestinal compartment to trap undissolved particles before the absorption compartment. The filter paper was protected from shear of the rotating magnetic stirring rod by supportive stainless steel mesh. Two glass vessels (5-liter capacity) were used as reservoirs using a valve to deliver fluid constantly at flow rate of $2 \mathrm{~mL} / \mathrm{min}$ from each vessel. Magnetic stirrers with heating facility were used for stirring in the gastric and intestinal compartments. The gastric reservoir was filled with $0.1 \mathrm{~N} \mathrm{HCl}$ and the intestinal reservoir was filled with $1.2 \mathrm{M}$ alkaline borate buffer ( $\mathrm{pH}$ 8.85). The gastric compartment was filled with $0.1 \mathrm{~N} \mathrm{HCl}$. The intestinal compartment was filled with 'pH-adjusted intestinal fluid' ( $\mathrm{pH}$ 7.2), which was prepared by mixing equal quantities of $0.1 \mathrm{~N} \mathrm{HCl}$ and $1.2 \mathrm{M}$ alkaline borate buffer. A pH electrode (Digital pH meter, Electroquip, Ahmedabad) was placed in the intestinal compartment for monitoring $\mathrm{pH}$ of ' $\mathrm{pH}$ adjusted intestinal fluid.'

Gohel et al. (13) had explained the comparison of the 

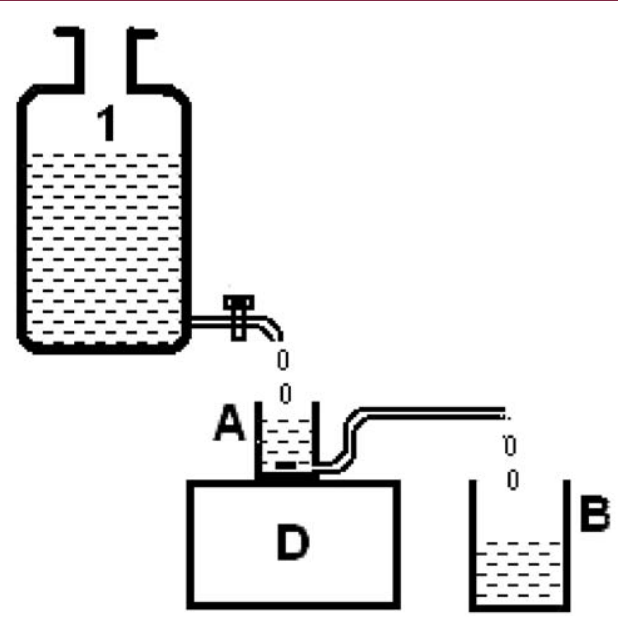

Figure 2. Modified Rossett-Rice Apparatus (only Gastric compartment) (13). 1 - Gastric Reservoir, A - Gastric Compartment, B - Sample collection beaker, $D$ - Magnetic stirrer with heating facility.

modified Rossett-Rice apparatus (only gastric compartment) with USP apparatus and other modified apparatus used to study dissolution of floating systems.

Table 1 shows the advantages of the proposed method by comparison with different methods suggested to study effect of $\mathrm{pH}$ change on poorly soluble weakly basic drug.

\section{Dissolution study}

The cinnarizine floating tablet was placed in the gastric compartment containing $70 \mathrm{~mL}$ of $0.1 \mathrm{~N} \mathrm{HCl}$. The magnetic stirrers were operated at $75 \mathrm{rpm}$ and the temperature of the dissolution media were maintained at $37 \pm 0.5^{\circ} \mathrm{C}$. From the reservoirs, $0.1 \mathrm{~N} \mathrm{HCl}$ and $1.2 \mathrm{M}$ alkaline borate buffer were added at a constant flow rate of $2 \mathrm{~mL} / \mathrm{min}$ to the gastric and intestinal compartments, respectively. The ' $\mathrm{pH}$-adjusted intestinal fluid' passed through the filter, eluted from the side arm containing dissolved cinnarizine, and was collected

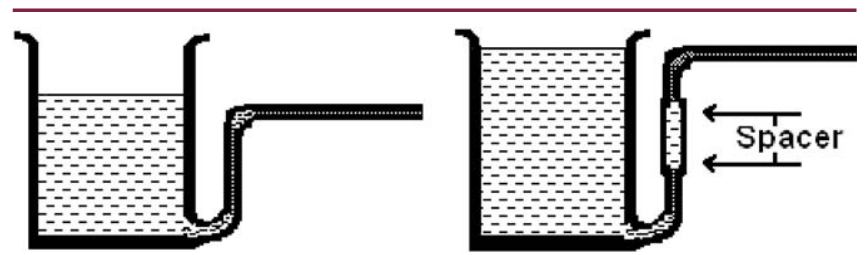

Figure 3. Compartment without Spacer and with Spacer

in the absorption compartment at the rate of $4 \mathrm{~mL} / \mathrm{min}$. Samples of $5 \mathrm{~mL}$ were collected from the absorption compartment at specified time intervals. Samples were analyzed using a UV/Visible spectrophotometer (Hitachi U2000, Japan) at $254 \mathrm{~nm}$.

Another cinnarizine floating tablet of similar preparation was evaluated using a modified Rossett-Rice dissolution apparatus (13) to study release of cinnarizine in $0.1 \mathrm{~N} \mathrm{HCl}$ (Figure 2).

The conventional cinnarizine tablet (Stugeron ${ }^{\circledR} 75 \mathrm{mg}$, Johnson \& Johnson) was also evaluated using the novel multicompartment dissolution apparatus. A second conventional cinnarizine tablet of similar preparation was evaluated using the modified Rossett-Rice apparatus. The basket was used to hold the conventional cinnarizine tablet in the gastric compartment of both apparatus, to protect it from the disintegrating strokes of the magnetic stirrer.

The concentrations of cinnarizine in the absorption compartment were monitored at specific time periods in each study.

The dissolution study of the cinnarizine tablet was also carried out by further modification of the multicompartment apparatus, to check the effect of variability in the volume of gastric fluid and intestinal fluid. The vertical glass tubes of the side arms of the gastric and intestinal compartments were cut from the center, and a spacer glass tube was incorporated at the center, such that the height of the vertical glass tube increased to hold more dissolution

Table 1: Comparison of various methods used to study effect of $\mathrm{pH}$ change on weakly basic drug

\begin{tabular}{|c|c|c|c|c|c|}
\hline Characteristics & $\begin{array}{l}\text { Transfer } \\
\text { Model } \\
\text { (7) }\end{array}$ & $\begin{array}{c}\text { Multi-compartment } \\
\text { Dissolution } \\
(9)\end{array}$ & $\begin{array}{c}\text { Absorption } \\
\text { Predicting system } \\
\text { (16) }\end{array}$ & $\begin{array}{l}\text { Multi-cell Dissolution } \\
\text { Equipment } \\
\text { (15) }\end{array}$ & $\begin{array}{c}\text { Proposed Novel } \\
\text { Multicompartment } \\
\text { Dissolution }\end{array}$ \\
\hline Compartments * & $\mathrm{G}, \mathrm{I}$ & $\mathrm{G}, \mathrm{I}, \mathrm{A}$ & $\mathrm{G}, \mathrm{I}, \mathrm{A}$ & $\mathrm{G}, \mathrm{I}, \mathrm{A}$ & $\mathrm{G}, \mathrm{I}, \mathrm{A}$ \\
\hline Floating dosage form & Not studied & Cannot use & Cannot use & Not studied & Can be use \\
\hline Pump for fluid transfer & Needed & Needed & Needed & Needed & No Need of pump \\
\hline pH change in "I" & Changed & Not changed & Not changed & Not changed & Not changed \\
\hline $\mathrm{pH}$ in "I" maintained by & - & $\mathrm{pH}$-stat equipment & $\begin{array}{l}\text { Addition of } \mathrm{pH} 12 \\
\text { solution }\end{array}$ & Addition of $\mathrm{NaOH}$ & $\begin{array}{l}\text { Addition of buffer } \\
\text { with high buffer } \\
\text { capacity }\end{array}$ \\
\hline Volume of "I" & Changed & Changed & Not changed & Not changed & Not changed \\
\hline IF Composition & Changed & Changed & Not changed & Not changed & Not changed \\
\hline
\end{tabular}


medium in the beaker (Figure 3). The dissolution of the floating tablet was carried out using $100 \mathrm{~mL}$ of $0.1 \mathrm{~N} \mathrm{HCl}$ and $500 \mathrm{~mL}$ of 'pH adjusted intestinal fluid.'

\section{Result and Discussion}

\section{Cinnarizine floating tablet}

Carbon dioxide is formed within a tablet containing effervescent agent when the tablet is brought in contact with the acidic dissolution medium. A low-density system is generated by entrapment of carbon dioxide gas in the gel network of HPMC. The gelling capacity of HPMC helps in floating as well as preventing disintegration of the tablet during the dissolution study and allows sustained release of cinnarizine. The tablets showed a lag time; the time required for initiation of floatation of the tablet was less than 1 minute.

\section{Novel multicompartment dissolution method}

The aim of the development of the novel multicompartment dissolution method is to mimic in vivo conditions to study the drug release from the floating system and the effect of change in $\mathrm{pH}$ during controlled release dissolution of released drug in the gastrointestinal tract. The proposed method is essentially a further improvement of the modified Rossett-Rice apparatus (13) by incorporation of an intestinal compartment and an absorption compartment.

The volumes of gastric compartment $(70-100 \mathrm{~mL})$ and intestinal compartment $(400-500 \mathrm{~mL})$ were set to mimic in vivo conditions $(13,9)$. Gastric juice release and gastric emptying through the pylorus opening is mimicked by addition of $0.1 \mathrm{~N} \mathrm{HCl}$ into the gastric compartment at a flow rate of $2 \mathrm{~mL} / \mathrm{min}$ and subsequent removal of content at the same rate by the side arm, maintaining a constant level in the compartment (13). Similarly, emptying of gastric content into the intestine and absorption of dissolved drug through a filter is mimicked in the intestinal compartment. Glass vessels (5-liter capacity) were selected as reservoirs to precisely maintain flow rate.

Cinnarizine is a lipophilic drug with a moderately high absorption rate constant of $0.01 \mathrm{~min}^{-1}(9)$, thus the output rate from the intestinal compartment to the absorption compartment was set at $4 \mathrm{~mL} / \mathrm{min}$ when the volume of' $\mathrm{pH}$ adjusted intestinal fluid' was $400 \mathrm{~mL}$. The gastric content output rate is $2 \mathrm{~mL} / \mathrm{min}$, and addition of 'another fluid' is required at 2 $\mathrm{mL} / \mathrm{min}$ to achieve a $4-\mathrm{mL} / \mathrm{min}$ output from the intestinal compartment. This fluid must have the capacity to maintain the $\mathrm{pH}$ of the intestinal compartment at 7.2 after addition of an equal volume of $0.1 \mathrm{~N} \mathrm{HCl}$. The $1.2 \mathrm{M}$ alkaline borate buffer $\mathrm{pH} 8.85$ was selected as 'another fluid' by trial and error method such that the 1:1 mixture of $0.1 \mathrm{~N} \mathrm{HCl}$ and 1.2 M alkaline borate buffer $\mathrm{pH} 8.85$ yields a $7.2 \mathrm{pH}$. The characteristic of this system is that dissolved drug in gastric fluid is exposed to the $7.2 \mathrm{pH}$ of the intestine. Addition of buffer with a high buffer capacity to neutralize $\mathrm{HCl}$ instead of using $\mathrm{NaOH}$ (15) ensures no drastic change in $\mathrm{pH}$ even after a minor change in flow rate and no subsequent interference with the analytical process. In the intestinal compartment, output of drug containing 'pH adjusted intestinal fluid' was maintained at 4
$\mathrm{mL} / \mathrm{min}$ along with simultaneous input of ' $\mathrm{pH}$ adjusted intestinal fluid' without drug at the same rate, thus virtually drug only is moving from the intestinal compartment to the absorption compartment mimicking the in vivo absorption.

\section{Dissolution Study}

The study of drug release using the modified Rossett-Rice apparatus (only the gastric compartment) can be considered as the study of drug release from the dosage form and its transfer into the intestinal compartment. The study of drug release using the novel multicompartment apparatus gives the results of drug transferred to the absorption compartment. Thus, the difference between total amount of drug transferred to the intestinal compartment and total amount of drug transferred to the absorption compartment gives the amount of drug being precipitated into the intestinal compartment due to the change in $\mathrm{pH}$.

Figure 4 shows the results of the dissolution testing of conventional cinnarizine tablet evaluated by the modified Rossett-Rice apparatus and by the novel multicompartment dissolution apparatus. Difference in cinnarizine release and cinnarizine transferred to the absorption compartment showed that approximately $50 \%$ of cinnarizine had been precipitated out into the intestinal compartment.

Figure 4 also shows the results of dissolution testing of the cinnarizine floating tablet evaluated by the modified Rossett-Rice apparatus and by the novel multicompartment dissolution apparatus. Total amount of cinnarizine that reached the absorption compartment was found to be $100 \%$, and plots of cinnarizine released and cinnarizine transferred to the absorption compartment were similar, which indicates that there was no precipitation of cinnarizine in the intestinal compartment. Hence, incorporation of poorly soluble weakly basic drugs into floating dosage forms to obtain better bioavailability is preferable.

As only the dissolved form of the drug is transferred from the intestinal compartment to the absorption compart-

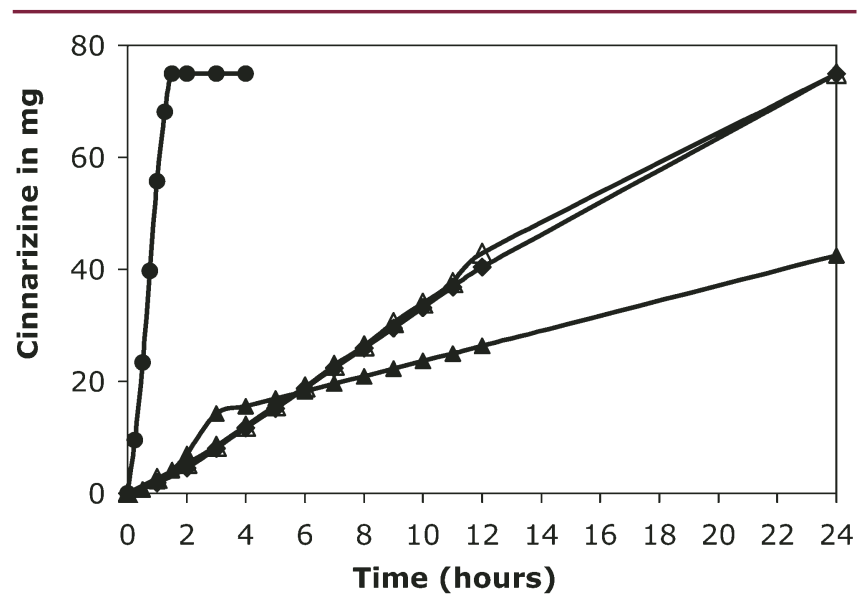

Figure 4. Dissolution profile of cinnarizine. Dissolution of conventional cinnarizine tablet:- - Cinnarizine released; - $\mathbf{\Delta}-$ Cinnarizine transferred to absorption compartment. Dissolution of floating cinnarizine tablet: $-\triangle-$ Cinnarizine released; $-\checkmark-$ Cinnarizine transferred to absorption compartment 
ment, the concentration of the dissolved drug remains similar in both compartments. However, total concentration of drug (dissolved and precipitated) may be higher in the intestinal compartment. Therefore, to determine the critical concentration of drug in the intestinal compartment when precipitation started, the concentration of drug in the absorption compartment was monitored at specific time periods.

Figure 5 shows that during dissolution study of conventional cinnarizine tablets, the maximum cumulative concentration achieved in the absorption compartment was 0.03 $\mathrm{mg} / \mathrm{mL}$ at $\mathrm{pH} 7.2$. This suggests that $0.03 \mathrm{mg} / \mathrm{mL}$ is a critical concentration above which cinnarizine precipitates. The difference between solubility of cinnarizine at pH 7.2 (0.002 $\mathrm{mg} / \mathrm{mL}$ ) and critical concentration can be explained by supersaturation of cinnarizine (7). After achieving critical concentration level, concentration in the absorption compartment decreases drastically to $0.0056 \mathrm{mg} / \mathrm{mL}$ (Figure 5). Crystal growth phenomena can explain this:once precipitation started in the intestinal compartment, concentration of soluble drug decreases noticeably (18). This also suggests that to prevent precipitation of drug in the intestinal compartment and to allow $100 \%$ transfer of drug from the intestinal compartment to the absorption compartment, maximum concentration in the intestinal compartment must never go beyond $0.03 \mathrm{mg} / \mathrm{mL}$. Figure 5 also shows that during the dissolution study of the floating cinnarizine tablet, the maximum concentration was found to be 0.015 $\mathrm{mg} / \mathrm{mL}$, thus no precipitation was observed.

Dissolution of the floating cinnarizine tablet was also carried out using the novel multicompartment dissolution apparatus, further modified by incorporation of a spacer to study the effect of variability of volume in vivo. However, the results of this dissolution study with and without the spacer showed negligible difference in cinnarizine transferred to the absorption compartment.

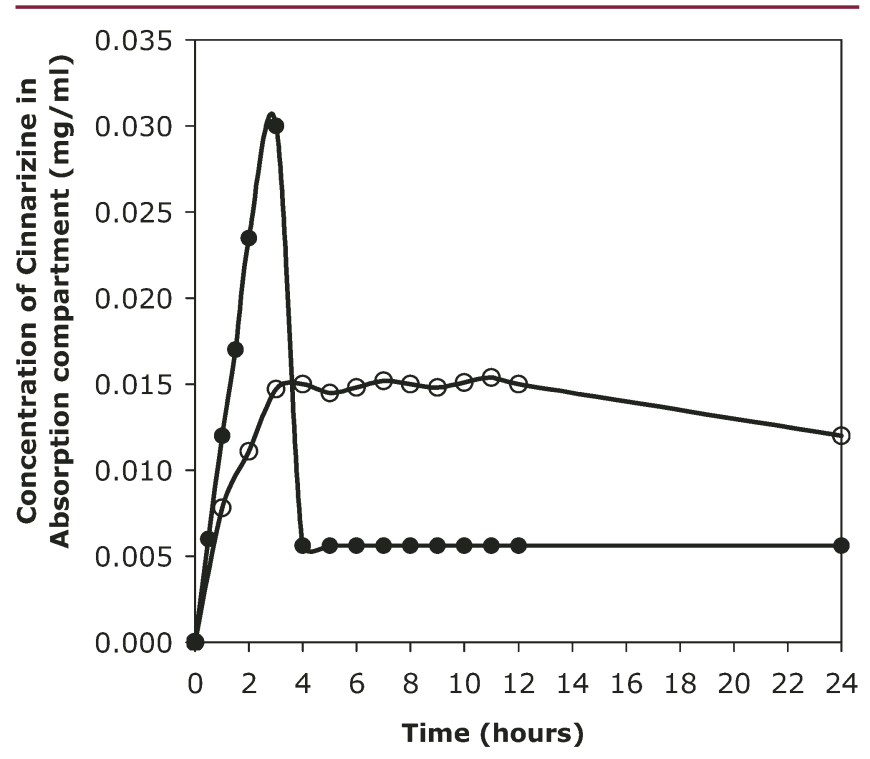

Figure 5. Concentration of cinnarizine in absorption compartment. - Conventional cinnarizine tablet; - $\bigcirc-$ Floating cinnarizine tablet
Dissolution testing using more biorelevant dissolution media with enzymes may be adopted by the researchers in the proposed method. Further studies may be carried out using Caco-2 or fiberglass dialysis membrane for better prediction of in vivo absorption.

\section{Conclusion}

In this study, a novel multicompartment dissolution apparatus was proposed to study drug release from a floating dosage form along with simultaneous study of the effect of change in $\mathrm{pH}$ of gastric and intestinal compartments on poorly soluble, weakly basic drugs. Gastric, intestinal, and absorption compartments were placed serially; the dosage form remained buoyant in the gastric compartment and released drug was allowed to transfer into the intestinal compartment and then to the absorption compartment. Because the absorption of drug can be predicted by the proposed method, the proposed method can establish good in vivo-in vitro correlation. The proposed method and novel apparatus are simple for the researcher to use and provide better predictive characteristics for determining in vivo absorption.

\section{Acknowledgement}

We are thankful to Carol Remedies and Zydus Cadila for providing cinnarizine and HPMC. We are also thankful to D. K. Scientific Pvt. Ltd. for modification of glass beakers.

\section{References}

1. Rouge, N.; Buri, P.; Doelker, E. Drug absorption sites in the gastro-intestinal tract and dosage forms for site specific delivery. Int. J. Pharm. 1996, 136, 117-139.

2. Deshpande, A. A.; Rhodes, C. T; Shah, N. H.; Malick, A. W. Controlled release drug delivery systems for prolonged gastric residence: an overview. Drug Dev. Ind. Pharm. 1996, 22, 531-539.

3. Conway, B. R. Drug delivery strategies for the treatment of helicobacter pylori infections. Current Pharm. Design 2005, 11, 775-790.

4. Singh, B. N.; Kim, K. H. Floating drug delivery systems: an approach to oral controlled drug delivery via gastric retention. J. Controlled Release 2000, 63, 235-259.

5. Klausner, E. A.; Lavy, E.; Friedman, M.; Hoffman, A. Expandable gastroretentive dosage forms. J. Controlled Release 2003, 90, 143-162.

6. Fujimori, J.; Machida, Y.; Tanaka, S.; Nagai, T. Effect of magnetically controlled gastric residence of sustained release tablet on bioavailability of acetaminophen. Int. J. Pharm. 1995, 119, 47-55.

7. Kostewicz, E. S.; Wunderlich, M.; Brauns, U.; Becker, R.; Bock, T.; Dressman, J. B. Prediction of precipitation of poorly soluble weak bases upon entry in the small intestine. J. Pharm. Pharmacol. 2004, 56, 43-51.

8. Chawla, G.; Gupta, P.; Koradia, V.; Bansal, A. K. Gastroretention: A means to address regional variability in intestinal drug absorption. Pharm. Tech. 2003, 27, 50-68. 
9. Gu, C.; Rao, D.; Gandhi, R. B.; Hilden, J.; Raghavan, K. Using a novel multicompartment dissolution system to predict the effect of gastric $\mathrm{pH}$ on the oral absorption of weak bases with poor intrinsic solubility. J. Pharm. Sci. 2005, 94 (1), 199-208.

10. Machida, Y.; Inouye, K.; Tokumara, T.; Iwata, M.; Nagai, T. Preparation and evaluation of intragastric buoyant preparations. Drug Des. Del. 1989, 4, 155-161.

11. Burns, S. J.; Corness, D.; Hay, G.; Higginbottom, S.; Whelan, I.; Attwood, D.; Barnwell, S. G. Development and validation of in vitro dissolution method for a floating dosage form with biphasic release characteristics. Int.J. Pharm. 1995, 121, 37-44.

12. Burns, S. J.; Attwood, D.; Barnwell, S. G. Assessment of a dissolution vessel designed for use with floating and erodible dosage forms. Int. J. Pharm. 1998, 160, 213-218.

13. Gohel, M. C.; Mehta, P. R.; Dave, R. K.; Bariya N. H. A more relevant dissolution method for evaluation of floating drug delivery system. Dissolution Tech. 2004, $11(4), 22-25$.
14. Allen, L. V.; Popovich, N. G.; Ansel H. C. Ansel's Pharmaceutical Dosage Forms and Drug Delivery Systems, $8^{\text {th }}$ ed.; Lippincott Williams and Wilkins: Philadelphia, 2004; pp 144-147.

15. Hughes, L.; Gehris, A. A new wave in dissolution testing. Rohm and Haas Research Labs. www.rohmhass. com/ionexchange/pharmaceuticals/Formulations_doc/ dissolution_testing_gi.pdf.

16. Kobayashi, M.; Sada, N.; Sugawara, M.; Iseki, K.; Miyazaki, K. Development of new system for prediction of drug absorption that takes into account drug dissolution and $\mathrm{pH}$ changes in the gastro-intestinal tract. Int. J. Pharm. 2001, 221, 87-94.

17. Blanquet, S.; Zeijdner, E.; Beyssac, E.; Meunier, J. P.; Denis, S.; Havenaar, R.; Alric, M. A dynamic artificial gastrointestinal system for studying behavior of orally administered drug dosage forms under various physiological conditions. Pharm. Res. 2004, 21 (4), 585-591.

18. Carstensen, J. T. Advanced Pharmaceutical Solids; Marcel Dekker: New York, 2001; pp 89-106. 